\title{
Estudo da influência de diferentes parâmetros na produção de enzimas líticas
}

\author{
Study of different parameters in the production of lytic enzymes
}

\author{
Luciana Francisco FLEURI ${ }^{1 *}$, Hélia Harumi SATO ${ }^{1}$
}

\section{Resumo}

O presente trabalho visou o estudo do efeito de diferentes variáveis na produção de $\beta$-1,3 glucanases, proteases e de quitinases pela linhagem Cellulosimicrobium cellulans 191, em meios de cultivo A, B e C, respectivamente. Foram realizados planejamentos fatoriais $2^{3}$, e os fatores estudados foram: $\mathrm{pH}$ inicial, temperatura e agitação dos frascos. No planejamento experimental para a produção de $\beta-1,3$ glucanase em meio de cultivo A foi verificada maior produção da enzima $\left(0,64 \mathrm{U} \cdot \mathrm{mL}^{-1}\right) \mathrm{com} \mathrm{pH}$ inicial de 8,5 após 24 horas de fermentação a $33^{\circ} \mathrm{C}$ e $200 \mathrm{rpm}$. Os parâmetros $\mathrm{pH}$, agitação dos frascos e interação entre todos os parâmetros foram estatisticamente significativos. No planejamento experimental para a produção de protease em meio de cultivo B foi verificada maior produção da enzima $\left(4,25 \mathrm{U}^{\left.-\mathrm{mL}^{-1}\right)}\right.$ com pH inicial de 6,5 após 30 horas de fermentação a $20^{\circ} \mathrm{C}$ e $200 \mathrm{rpm}$. O pH foi o único parâmetro estatisticamente significativo. No planejamento experimental para a produção de quitinase em meio de cultivo $\mathrm{C}$ foi verificada maior produção da enzima $\left(7,06 \mathrm{U} \cdot \mathrm{mL}^{-1}\right)$ com pH inicial de 5,5 após 72 horas de fermentação a $25^{\circ} \mathrm{C}$ e $200 \mathrm{rpm}$. Todos os parâmetros estudados e suas interações foram estatisticamente significativos. Os coeficientes de determinação, as análises de variância e os teste $F$ demonstraram que os modelos de primeira ordem obtidos foram considerados estatisticamente significativos adotando um nível de confiança de $95 \%$.

Palavras-chave: $\beta-1,3$ glucanases; proteases; quitinases; Cellulosimicrobium cellulans 191.

\begin{abstract}
The aim of this work was to study the effects of different parameters in the production of $\beta-1,3$ glucanases, proteases and chitinases by Cellulosimicrobium celulans 191, in culture media A, B and C, respectively. The experimental designs employed were $2^{3}$ factorial designs, and the factors studied were: initial $\mathrm{pH}$, temperature and rotary shaker speed. The experimental results for the production of $\beta-1,3$ glucanase in culture medium A showed maximum activity $\left(0.64 \mathrm{U} \cdot \mathrm{mL}^{-1}\right)$ with an initial $\mathrm{pH}$ of 8.5 after 24 hours of fermentation at $33^{\circ} \mathrm{C}$ and $200 \mathrm{rpm}$. The parameters $\mathrm{pH}$, rotary shaker speed and the interaction of all the parameters presented statistical significance. The experimental results for protease production in culture medium B showed maximum activity $\left(4.25 \mathrm{U}_{\mathrm{mL}}^{-1}\right)$ with an initial $\mathrm{pH}$ of 6.5 after 30 hours of fermentation at $20^{\circ} \mathrm{C}$ and $200 \mathrm{rpm}$. The $\mathrm{pH}$ was the only parameter that presented statistical significance. The experimental results for chitinase production in culture medium C showed maximum activity $\left(7.06 \mathrm{U} \cdot \mathrm{mL}^{-1}\right)$ at an initial pH of 5.5 after 72 hours of fermentation at $25^{\circ} \mathrm{C}$ and $200 \mathrm{rpm}$. All the parameters and their interactions presented statistical significance. The determination coefficients of the analysis of variance and $F$ tests demonstrated that the linear regression models obtained were significant at a confidence level of $95 \%$.
\end{abstract}

Keywords: $\beta-1,3$ glucanases; proteases; chitinases; Cellulosimicrobium cellulans 191.

\section{Introdução}

A parede celular de leveduras é formada por três principais grupos de polissacarídeos: $\beta$-glucana $(\beta-1,3$ glucana e $\beta$-1,6 glucana), mananaproteínas e quitina. A $\beta$-glucana é o composto majoritário da parede celular de leveduras, seguida pelas mananaproteínas e pela quitina. A camada externa da parede celular de leveduras é formada pelas mananaproteínas, enquanto a interna, pela glucana (ANDREWS; ASENJO, 1987a,b). Diferentemente da parede celular das leveduras, a parede celular de fungos é composta principalmente por quitina (SAHAI; MANOCHA, 1993).

As $\beta-1,3$ glucanases, proteases líticas e quitinases são capazes de hidrolisar componentes da parede celular de microrganismos e, por isso, apresentam atividade lítica sobre leveduras e fungos (SELITRENIKOFF, 2001).
Modelos matemáticos têm sido cada vez mais utilizados para ajudar a explicar respostas de reações bioquímicas. A metodologia de superfície de resposta é freqüentemente usada para determinar uma resposta ótima entre uma faixa específica de condições experimentais. Em muitos casos, a interação de parâmetros que influenciam processos fermentativos pode ser avaliada com um número reduzido de ensaios através de um planejamento experimental (THÉODORE; PANDA, 1995). Em relação às enzimas líticas, a metodologia de superfície de resposta é freqüentemente utilizada para a otimização e verificação da influência dos componentes do meio de cultivo para a produção das enzimas, assim como para a otimização e a verificação da influência de parâmetros na produção enzimática.

Recebido para publicação em 31/7/2006

Aceito para publicação em 19/2/2008 (001807)

${ }^{1}$ Laboratório de Bioquímica de Alimentos, Departamento de Ciência de Alimentos, Faculdade de Engenharia de Alimentos, Universidade Estadual de Campinas - Unicamp,

Rua Monteiro Lobato, 80, CP 6121, CEP 13083-862, Campinas - SP, Brasil, E-mail: luciana@fea.unicamp.br

${ }^{*}$ A quem a correspondência deve ser enviada 
Soares (2002) estudou a produção da $\beta-1,3$ glucanase pela linhagem C. cellulans 191. O microrganismo foi cultivado em meio contendo diferentes tipos de indutores e as condições de cultivo foram otimizadas através do planejamento experimental para o aumento da produção da enzima. O meio de cultivo selecionado para a maior produção de $\beta-1,3$ glucanase continha $0,20 \%$ de $\left(\mathrm{NH}_{4}\right)_{2} \mathrm{SO}_{4} ; 0,02 \%$ de $\mathrm{MgSO}_{4} .7 \mathrm{H}_{2} \mathrm{O}$ e $1,0 \%$ de parede celular de levedura extraída mecanicamente em Dyno-Mill utilizada como indutor em tampão fosfato $0,2 \mathrm{M}$, $\mathrm{pH} 7,5$. Após otimização obteve-se cerca de $75 \%$ a mais de atividade de $\beta-1,3$ glucanase em relação às condições originais de fermentação.

Estudos complementares da protease lítica da linhagem C. cellulans 191 foram desenvolvidos por Santos (2004). O meio para a produção de protease lítica foi otimizado por planejamento experimental e apresentou a seguinte composição: 2,0 g.L $\mathrm{L}^{-1} \mathrm{de}$ $\left(\mathrm{NH}_{4}\right)_{2} \mathrm{SO}_{4} ; 0,2$ g.L $\mathrm{L}^{-1}$ de $\mathrm{MgSO}_{4} \cdot 7 \mathrm{H}_{2} \mathrm{O}$ e 80 g.L $\mathrm{L}^{-1}$ de levedura seca utilizada como indutor em tampão fosfato $0,15 \mathrm{M}, \mathrm{pH} 8,0$.

Adinarayana e Ellaiah (2002) otimizaram os componentes do meio de cultivo para produção de protease utilizando planejamento fatorial completo $2^{3}$. Os valores ótimos das variáveis testadas para a máxima produção da enzima foram: 7,98 g.L $\mathrm{L}^{-1}$ de glicose; 9,54 g. $\mathrm{L}^{-1}$ de peptona e 8,75 g. $\mathrm{L}^{-1}$ de solução salina. Segundo os autores, o método foi eficiente, somente 20 experimentos foram necessários para determinar as condições ótimas, o modelo foi satisfatório e o coeficiente de determinação foi de 0,94 .

Vaidya et al. (2003) otimizaram os componentes do meio de cultivo para a produção de quitinase pela bactéria Alcaligenes xylosoxydans IMI 385022. Os componentes considerados relevantes para a produção de quitinase através do planejamento de Plackett-Burman foram: Tween 20, extrato de levedura e quitina. A concentração ótima dos componentes foi: 1,0 g. $\mathrm{L}^{-1}$ de $\left(\mathrm{NH}_{4}\right)_{2} \mathrm{SO}_{4} ; 1,36$ g.L $\mathrm{L}^{-1}$ de $\mathrm{KH}_{2} \mathrm{PO}_{4} ; 0,3$ g. $\mathrm{L}^{-1}$ de $\mathrm{MgSO}_{4} \cdot 7 \mathrm{H}_{2} \mathrm{O}$; 0,12 g.L $\mathrm{L}^{-1}$ de Tween 20; 0,3 g.L. $\mathrm{L}^{-1}$ de extrato de levedura e 15 g.L. $\mathrm{L}^{-1}$ de quitina. Segundo os autores a produção de quitinase aumentou aproximadamente 2,41 vezes.

A otimização das condições de cultivo para a produção de $\beta$-glucanase por Bacillus subtilis ZJF 1A5 foi estudada em frascos agitados. A temperatura apresentou grande efeito na produção da enzima, sendo a temperatura ótima de $37^{\circ} \mathrm{C}$. A atividade diminuiu significativamente quando se utilizaram temperaturas superiores. A quantidade de meio utilizada nos frascos afetou substancialmente a produção da $\beta$-glucanase. Os resultados do planejamento fatorial fracionário mostraram que o tempo de crescimento e tamanho do inóculo e a velocidade de agitação dos frascos foram fatores significativos para a produção e para o período de tempo para se obter maior atividade da enzima. As condições ótimas para a produção enzimática obtidas no planejamento composto central foram: tempo de incubação do inóculo de 16 horas; quantidade do inóculo de 3,82\%; agitação dos frascos de $210 \mathrm{rpm} ; 30 \mathrm{~mL}$ de meio de cultivo em frascos de $250 \mathrm{~mL}$; $\mathrm{pH}$ inicial de 7,0; temperatura de $37^{\circ} \mathrm{C}$ e tempo de incubação para a maior produção enzimática de 50 horas (HE et al., 2003).
O planejamento fatorial fracionário $2^{6-2}$ foi aplicado para elucidar os componentes do meio de cultivo que afetam significativamente a produção da enzima $\beta$-glucanase de Bacillus subtilis ZJF1A5. A concentração da farinha de cevada, da farinha de milho e da farinha de soja no meio foram fatores significativos. O método de análise da direção ascendente de máxima inclinação foi usado para localizar o ponto ótimo. As curvas de nível do planejamento composto central foram utilizadas para representar a superfície de resposta quadrática proveniente dos níveis dos fatores para a máxima produção enzimática. A composição do meio de fermentação otimizado com a metodologia de superfície de resposta foi de 63,5 g. $\mathrm{L}^{-1}$ de farinha de cevada; 44,8 g.L. $\mathrm{L}^{-1}$ de farinha de milho; $1,0 \mathrm{~g} . \mathrm{L}^{-1}$ de $\mathrm{KH}_{2} \mathrm{PO}_{4}$; 0,1 g.L.- de $\mathrm{MgSO}_{4} \cdot 7 \mathrm{H}_{2} \mathrm{O} ; 0,1$ g. $\mathrm{L}^{-1}$ de $\mathrm{CaCl}_{2}$. A atividade da enzima após 48 horas de fermentação foi cerca de 1,4 vezes maior que a atividade enzimática obtida no meio original (TANG et al., 2004).

Beshay et al. (2003) descreveram a produção de $\beta-1,3$ glucanase de Bacillus sp. utilizando uma linhagem de Escherichia coli recombinante. A produção máxima de $\beta-1,3$ glucanase ocorreu após 28 horas de fermentação, utilizando um meio de cultivo otimizado composto por 7,0 g. $\mathrm{L}^{-1} \mathrm{de}$ lactose; 24,0 g.L $\mathrm{L}^{-1}$ de extrato de levedura e 5,0 g. $\mathrm{L}^{-1}$ de $\mathrm{NaCl}$.

As enzimas líticas produzidas pela linhagem Cellulosimicrobium cellulans 191 são capazes de lisar células de leveduras, e por isso apresentam grandes perspectivas em diversos ramos biotecnológicos (FLEURI; SATO, 2005). Proteases, $\beta-1,3$ glucanases e quitinases são capazes de lisar a parede celular de Saccharomyces cerevisiae, Candida sp. e outros gêneros de leveduras, e as preparações enzimáticas com alto teor de quitinases são capazes de inibir o crescimento de fungos como Trichoderma harzianum e Aspergillus niger (SCOTT; SCHEKMAN, 1980; PATIL; GHORMADE; DESHPANDE, 2000).

Este trabalho teve como objetivo avaliar o efeito de diferentes parâmetros na produção de $\beta-1,3$ glucanases, proteases líticas e quitinases pela linhagem Cellulosimicrobium cellulans 191, utilizando planejamento experimental e a metodologia de superfície de resposta.

\section{Material e métodos}

\subsection{Material}

Foram utilizados os seguintes reagentes: caseína Hammarsten e ácido tricloroacético (Merck), ácidos, bases, sais e minerais (Merck, Riedel, Ecibra ou equivalente).

Além dos materiais específicos: laminarina (polissacarídeo composto de unidades de $\beta-1,3$ glicose, obtido da alga Laminaria digitata) (Sigma); parede celular bruta de levedura Saccharomyces cerevisiae (Prodesa); levedura seca (Fleischmann) e quitina de crustáceos.

E o microrganismo que lisa a parede celular de leveduras:

- A bactéria Cellulosimicrobium cellulans 191 foi utilizada para a produção das enzimas líticas $\beta-1,3$ glucanases, proteases e quitinases; e 
- A linhagem bacteriana foi isolada de resíduos de usina de fermentação alcoólica, por Ferro (2002), no Laboratório de Bioquímica de Alimentos da Faculdade de Engenharia de Alimentos da Universidade Estadual de Campinas.

\subsection{Métodos}

\section{Manutenção do microrganismo}

O microrganismo que lisa leveduras foi mantido em tubos inclinados com meio ágar TYM descrito por Yamamoto et al. (1993). A cultura vem sendo conservada a $4{ }^{\circ} \mathrm{C}$ sob camada de vaselina esterilizada e repicada a cada três meses de armazenamento.

Estudo do efeito do $\mathrm{pH}$, temperatura e agitação na produção de $\beta-1,3$ glucanases, proteases e quitinases, utilizando planejamento experimental

Foram realizados 11 ensaios para o estudo da produção de cada enzima, tratando-se de um planejamento fatorial $2^{3} \mathrm{com}$ 3 pontos centrais, onde n é o número de variáveis independentes, conforme metodologia descrita por Neto et al. (2001). Para cada ensaio, realizado de maneira aleatória, foram coletadas alíquotas após diferentes tempos de fermentação. A análise estatística dos resultados foi realizada através do programa computacional Statistica for Windows versão 5.0 (STATISTICA, 1995), utilizando o Experimental Design.

Preparação do pré-inóculo: uma alçada da cultura de 24 horas do microrganismo em tubos inclinados de meio TYM foi inoculada separadamente em frascos Erlenmeyers de $500 \mathrm{~mL}$ contendo $100 \mathrm{~mL}$ do meio de cultivo.

Fermentação: alíquotas de $10 \mathrm{~mL}$ do pré-inóculo foram transferidas assepticamente para frascos Erlenmeyers de $500 \mathrm{~mL}$ contendo $90 \mathrm{~mL}$ do mesmo meio de cultivo. Os frascos foram incubados sob diferentes condições, em diferentes tempos de fermentação, conforme os ensaios do planejamento experimental.

Obtenção do extrato enzimático bruto: após a incubação, os meios de cultivo obtidos no item anterior foram centrifugados a 7.840 g durante 10 minutos a $5{ }^{\circ} \mathrm{C}$, e os sobrenadantes foram utilizados como fonte de enzima.

As atividades de $\beta-1,3$ glucanases, proteases e quitinases nos sobrenadantes dos meios de cultivo foram determinadas como descrito a seguir.

\section{Estudo da produção de $\beta$-1,3 glucanases}

A produção de $\beta$-1,3 glucanases pela linhagem C. cellulans 191 foi testada, em frascos agitados, em meio de cultivo A composto por 2,0 g.L $\mathrm{L}^{-1}$ de $\left(\mathrm{NH}_{4}\right)_{2} \mathrm{SO}_{4} ; 0,2 \mathrm{~g} . \mathrm{L}^{-1}$ de $\mathrm{MgSO}_{4} .7 \mathrm{H}_{2} \mathrm{O}$ e 10 g.L $\mathrm{L}^{-1}$ de parede celular de levedura utilizada como indutor em tampão fosfato 0,2 M, pH 7,5, otimizado por Soares (2002).

As variáveis independentes e seus respectivos níveis e valores reais do planejamento fatorial estão apresentados na Tabela 1.
Para os valores de pH 6,5 e 7,5 foi utilizado tampão fosfato $0,2 \mathrm{M}$, enquanto que para o valor de $\mathrm{pH} 8,5$ foi utilizado tampão carbonato-bicarbonato $0,2 \mathrm{M}$.

As melhores condições selecionadas a partir do planejamento experimental para a produção de $\beta-1,3$ glucanase foram utilizadas para a fermentação da linhagem C. cellulans $191 \mathrm{em}$ frascos Erlenmeyers aletados.

\section{Estudo da produção de proteases}

A produção de proteases pela linhagem C. cellulans 191 foi testada, em frascos agitados, em meio de cultivo B composto por 2,0 g.L $\mathrm{L}^{-1}$ de $\left(\mathrm{NH}_{4}\right)_{2} \mathrm{SO}_{4} ; 0,2$ g.L $\mathrm{L}^{-1}$ de $\mathrm{MgSO}_{4} .7 \mathrm{H}_{2} \mathrm{O}$ e 80 g.L $\mathrm{L}^{-1}$ de levedura seca utilizada como indutor em tampão fosfato 0,15 M, pH 8,0, otimizado por Santos (2004).

As variáveis independentes e seus respectivos níveis e valores reais estão apresentados na Tabela 2.

\section{Estudo da produção de quitinases}

A produção de quitinases pela linhagem C. cellulans 191 foi testada, em frascos agitados, em meio de cultivo $\mathrm{C}$ composto por 4,0 g. $\mathrm{L}^{-1}$ de extrato de levedura; 2,0 g. $\mathrm{L}^{-1}$ de triptona; 4,0 g. $\mathrm{L}^{-1}$ de $\mathrm{MgSO}_{4} .7 \mathrm{H}_{2} \mathrm{O} ; 1,2$ g.L $\mathrm{L}^{-1}$ de $\mathrm{KH}_{2} \mathrm{PO}_{4}$; 2,8 g. $\mathrm{L}^{-1}$ de $\mathrm{K}_{2} \mathrm{HPO}_{4}$ e 15 g. $\mathrm{L}^{-1}$ de quitina neutralizada utilizada como indutor, otimizado por Yamaguchi (2003). Este meio de cultivo apresenta $\mathrm{pH}$ 6,5. Foram utilizadas soluções de $\mathrm{HCl}$ e $\mathrm{NaOH}$ para ajustar os valores de $\mathrm{pH}$ dos meios de cultivo.

As variáveis independentes e seus respectivos níveis e valores reais estão apresentados na Tabela 3.

Tabela 1. Variáveis independentes, níveis e valores reais utilizados no planejamento fatorial para o estudo da produção de $\beta$-1,3 glucanases.

\begin{tabular}{lccc}
\hline Variáveis independentes & \multicolumn{3}{c}{ Níveis } \\
\cline { 2 - 4 } & -1 & 0 & +1 \\
\hline $\mathrm{pH}$ & 6,5 & 7,5 & 8,5 \\
Temperatura $\left({ }^{\circ} \mathrm{C}\right)$ & 27 & 30 & 33 \\
Agitação $(\mathrm{rpm})$ & 100 & 150 & 200 \\
\hline
\end{tabular}

Tabela 2. Variáveis independentes, níveis e valores reais utilizados no planejamento fatorial para o estudo da produção de proteases.

\begin{tabular}{lccc}
\hline Variáveis independentes & \multicolumn{3}{c}{ Níveis } \\
\cline { 2 - 4 } & -1 & 0 & +1 \\
\hline $\mathrm{pH}$ & 6,5 & 8,0 & 9,5 \\
Temperatura $\left({ }^{\circ} \mathrm{C}\right)$ & 20 & 30 & 40 \\
Agitação $(\mathrm{rpm})$ & 100 & 150 & 200 \\
\hline
\end{tabular}

Tabela 3. Variáveis independentes, níveis e valores reais utilizados no planejamento fatorial para o estudo da produção de quitinases.

\begin{tabular}{lccc}
\hline Variáveis independentes & \multicolumn{3}{c}{ Níveis } \\
\cline { 2 - 4 } & -1 & 0 & +1 \\
\hline pH & 5,5 & 6,5 & 7,5 \\
Temperatura $\left({ }^{\circ} \mathrm{C}\right)$ & 25 & 30 & 35 \\
Agitação $(\mathrm{rpm})$ & 100 & 150 & 200 \\
\hline
\end{tabular}


Determinação das atividades enzimáticas

Determinação da atividade de $\beta-1,3$ glucanase

A atividade de $\beta-1,3$ glucanase foi determinada como descrito por Saeki et al. (1994) e Santos (2000). A mistura de $250 \mu \mathrm{L}$ de solução enzimática e $250 \mu \mathrm{L}$ de solução 1,0\% de laminarina em tampão acetato de sódio $0,1 \mathrm{M}, \mathrm{pH} 5,5$ foi incubada a $55^{\circ} \mathrm{C}$ por 30 minutos. A reação foi interrompida por aquecimento a $100{ }^{\circ} \mathrm{C}$ por 5 minutos. Os açúcares redutores foram determinados pelo método de Somogyi (1952) utilizando-se glicose como açúcar padrão. Para controle foram determinados os açúcares redutores presentes na solução enzimática utilizando-se água destilada no lugar da solução de laminarina. Para ajuste do espectrofotômetro foi preparado um tubo branco utilizando-se água destilada no lugar da solução de laminarina. Uma unidade de atividade foi definida como a liberação de um $\mu$ moL de glicose por minuto por $\mathrm{mL}$ de solução enzimática.

\section{Determinação da atividade de protease lítica}

A atividade de protease foi determinada utilizando-se caseína como substrato, como descrito por Obata et al. (1977) e Rowley e Bull (1977). A mistura de reação contendo 1,5 mL de solução 2,0\% de caseína; 1,0 mL de tampão fosfato $0,15 \mathrm{M}$, $\mathrm{pH} 7,5$ e $0,5 \mathrm{~mL}$ de solução enzimática foi incubada a $30^{\circ} \mathrm{C}$ por 30 minutos. A reação foi paralisada pela adição de $3,0 \mathrm{~mL}$ de solução 0,4 M de ácido tricloroacético (TCA), seguida de filtração em papel Whatman 42. A absorbância do filtrado foi determinada a $280 \mathrm{~nm}$, sendo uma unidade de atividade definida como aquela capaz de aumentar em uma unidade a absorbância do filtrado, nas condições do ensaio. Foi preparado um tubo branco para cada amostra, com a adição de TCA antes da adição da enzima.

\section{Determinação da atividade de quitinase}

A atividade de quitinase foi determinada usando quitina coloidal (RÉISSIG; STROMINGER; LELOIR, 1955; SANDHU; WADHWA; BAGGA, 1989), de acordo com a metodologia otimizada por Yamaguchi (2003). A quitina coloidal foi preparada como descrito por Fleuri (2005). A mistura de 0,5 mL de solução enzimática e $0,5 \mathrm{~mL}$ de suspensão de quitina coloidal $0,2 \% \mathrm{em}$ tampão citrato de sódio $0,1 \mathrm{M}, \mathrm{pH}$ 6,0 foi incubada durante 60 minutos a $45^{\circ} \mathrm{C}$. A mistura de reação foi resfriada em banho de gelo e centrifugada a 8.232 g por 10 minutos a $5^{\circ} \mathrm{C}$. A mistura de $1,0 \mathrm{~mL}$ do sobrenadante e $50 \mu \mathrm{L}$ de borato de potássio $0,8 \mathrm{M}$ foi aquecida em banho em ebulição por 3 minutos e resfriada em banho de gelo. Em seguida foi adicionado 1,5 mL de solução $10 \%$ de dimetilaminobenzaldeído em ácido acético contendo $12,5 \%$ de $\mathrm{HCl} 10 \mathrm{~N}$. A mistura foi incubada em banho-maria a $37^{\circ} \mathrm{C}$ durante 20 minutos e a absorbância foi determinada a $585 \mathrm{~nm}$. Para a preparação do tubo branco foi utilizada solução enzimática inativada através de aquecimento durante 5 minutos em banho em ebulição. Uma unidade de atividade foi definida como $1 \mu \mathrm{moL}$ de $\mathrm{N}$-acetilglicosamina formado nas condições do ensaio.

Todos os testes para a determinação das atividades enzimáticas foram realizados em duplicatas.

\section{Resultados e discussão}

\subsection{Estudo do efeito de pH, temperatura e agitação na produção de $\beta-1,3$ glucanases, proteases e quitinases, utilizando planejamento experimental}

\section{Estudo da produção de $\beta$-1,3 glucanase}

Foi realizado um planejamento fatorial $2^{3}+3$ pontos centrais para avaliar as variáveis independentes $\mathrm{pH}$, temperatura e agitação dos frascos na produção de $\beta-1,3$ glucanases pela linhagem C. cellulans 191.

A Tabela 4 mostra o planejamento fatorial para a produção da enzima, com seus valores reais e codificados para cada ensaio, assim como a variável dependente, ou seja, a atividade de $\beta$-1,3 glucanase (U.mL ${ }^{-1}$ ).

A análise estatística foi realizada com os valores de atividade enzimática obtidos após 24 horas de fermentação, em que foi obtida maior atividade de $\beta-1,3$ glucanase (Ensaio 8) (Tabela 4).

Analisando os valores de atividade obtidos na Tabela 4 após 24 horas de fermentação, verifica-se um incremento na atividade de $\beta-1,3$ glucanase ao longo do planejamento, variando de 0,03 U.mL ${ }^{-1}$ de $\beta-1,3$ glucanase para o ensaio $3\left(\mathrm{pH} 6,5,33^{\circ} \mathrm{C}\right.$ e $100 \mathrm{rpm}$ ) até $0,64 \mathrm{U} \cdot \mathrm{mL}^{-1}$ de $\beta-1,3$ glucanase para o ensaio 8 ( $\mathrm{pH} 8,5,33^{\circ} \mathrm{C}$ e $200 \mathrm{rpm}$ ). Os 11 experimentos realizados em diferentes condições após 24 horas de fermentação fornecem informações importantes relacionadas ao ganho de atividade enzimática e a importância de se conhecer e estabelecer condições adequadas para a produção da enzima. Além disso, indicam as condições a serem utilizadas para a otimização da produção da enzima por meio de planejamento composto central rotacional.

A Tabela 5 apresenta o efeito das variáveis sobre a produção de $\beta$-1,3 glucanase. $\mathrm{O}$ pH e a agitação apresentaram efeitos positivos significativos na atividade enzimática, ou seja, o aumento dos valores destes parâmetros dentro da faixa estudada incrementaria a produção da enzima. No entanto, a temperatura individualmente (na faixa estudada) não afetou a produção de $\beta-1,3$ glucanase, mas sua interação com o pH e a agitação geraram efeitos positivos significativos. $\mathrm{O} \mathrm{pH}$ exerceu o maior efeito na resposta, seguido pela agitação. Dessa forma verificou-se que as condições para se obter maior produção de $\beta-1,3$ glucanase pela linhagem C. cellulans 191, dentre os valores estudados, são: valores de $\mathrm{pH}$ acima de 6,5 e agitação dos frascos superior a $100 \mathrm{rpm}$. Escolheu-se pH 7,5, levando-se em consideração que $\mathrm{pH}$ muito elevado pode diminuir a estabilidade da enzima (FERRO, 2002). Para a produção da enzima $\beta-1,3$ glucanase pela linhagem Cellulosimicrobium cellulans 191 foi escolhido $200 \mathrm{rpm}$ para a agitação dos frascos e $30^{\circ} \mathrm{C}$.

A Tabela 6 apresenta os coeficientes de regressão, erros padrão e limites de confiança para a produção de $\beta-1,3$ glucanase. Os valores de t e p apresentados na Tabela 5 e os coeficientes de regressão da Tabela 6 foram utilizados para a construção do modelo linear a partir das variáveis estudadas. Os valores de $\mathrm{p}$ são utilizados para checar a significância de cada coeficiente e 
Tabela 4. Estudo do efeito do $\mathrm{pH}$, temperatura e agitação na produção de $\beta-1,3$ glucanases pela linhagem C. cellulans 191.

\begin{tabular}{|c|c|c|c|c|c|c|}
\hline \multirow[t]{3}{*}{ Ensaios* } & \multirow[t]{3}{*}{$\mathrm{pH}$} & \multirow[t]{3}{*}{ Temperatura $\left({ }^{\circ} \mathrm{C}\right)$} & \multirow[t]{3}{*}{ Agitação (rpm) } & \multicolumn{3}{|c|}{ Tempo de fermentação } \\
\hline & & & & 18 horas & 24 horas & 30 horas \\
\hline & & & & \multicolumn{3}{|c|}{ Atividade de $\beta-1,3$ glucanase $\left(\mathrm{U} \mathrm{mL}^{-1}\right)$} \\
\hline 1 & $-1(6,5)$ & $-1(27)$ & $-1(100)$ & 0,05 & 0,07 & 0,06 \\
\hline 2 & $+1(8,5)$ & $-1(27)$ & $-1(100)$ & 0,20 & 0,29 & 0,28 \\
\hline 3 & $-1(6,5)$ & $+1(33)$ & $-1(100)$ & 0,02 & 0,03 & 0,03 \\
\hline 4 & $+1(8,5)$ & $+1(33)$ & $-1(100)$ & 0,21 & 0,27 & 0,25 \\
\hline 5 & $-1(6,5)$ & $-1(27)$ & $+1(200)$ & 0,08 & 0,10 & 0,09 \\
\hline 6 & $+1(8,5)$ & $-1(27)$ & $+1(200)$ & 0,35 & 0,45 & 0,43 \\
\hline 7 & $-1(6,5)$ & $+1(33)$ & $+1(200)$ & 0,07 & 0,09 & 0,09 \\
\hline 8 & $1(8,5)$ & $+1(33)$ & $+1(200)$ & 0,51 & 0,64 & 0,62 \\
\hline 9 & $0(7,5)$ & $0(30)$ & $0(150)$ & 0,23 & 0,29 & 0,27 \\
\hline 10 & $0(7,5)$ & $0(30)$ & $0(150)$ & 0,21 & 0,30 & 0,24 \\
\hline 11 & $0(7,5)$ & $0(30)$ & $0(150)$ & 0,24 & 0,31 & 0,25 \\
\hline
\end{tabular}

*Aleatorizados previamente à experimentação.

Tabela 5. Estimativa dos efeitos das variáveis independentes na produção de $\beta-1,3$ glucanase.

\begin{tabular}{lccrc}
\hline \multicolumn{1}{c}{ Parâmetros } & Efeito & Erro padrão & \multicolumn{1}{c}{$\mathrm{t}(2)$} & $\mathrm{P}$ \\
\hline Média & 0,26 & 0,003 & 85,63 & 0,0001 \\
1 - pH $(\mathrm{L})^{*}$ & 0,34 & 0,007 & 48,08 & 0,0004 \\
2- Temperatura (L) & 0,03 & 0,007 & 4,24 & 0,0513 \\
3 - Agitação (L) & 0,16 & 0,007 & 21,92 & 0,0021 \\
$1 \times 2^{*}$ & 0,06 & 0,007 & 7,78 & 0,0161 \\
$1 \times 3^{*}$ & 0,11 & 0,007 & 15,56 & 0,0041 \\
$2 \times 3^{*}$ & 0,06 & 0,007 & 8,49 & 0,0136 \\
\hline
\end{tabular}

${ }^{\star}$ Parâmetros estatisticamente significativos; e (L) parâmetro linear.

também indicam a importância de cada variável ou interação entre variáveis na resposta do modelo. Quanto maior a magnitude do valor de t e menor o valor de p, maior será a significância do coeficiente.

A validade do modelo foi verificada pela Análise de Variância (ANOVA) apresentada na Tabela 7. O coeficiente de determinação obtido foi de 0,96 . O valor do teste $F$ calculado foi comparado ao valor do $\mathrm{F}$ tabelado para a distribuição de $\mathrm{F}$ a 95\% de nível de confiança com os respectivos graus de liberdade. O F calculado para a produção de $\beta-1,3$ glucanase pela linhagem C. cellulans 191 foi 4,73 vezes maior do que o F tabelado, indicando que o modelo de primeira ordem é estatisticamente significativo e preditivo e descreve as respostas em função das variáveis analisadas.

Os coeficientes de regressão não estatisticamente significativos a 95\% de nível de confiança foram excluídos do modelo, sendo incorporados no resíduo total. A partir da validação dos parâmetros de estudo, obteve-se o modelo linear, que representa o comportamento da atividade enzimática e descreve as superfícies de resposta e curvas de contorno (Figura 1) da produção de $\beta-1,3$ glucanase pela linhagem Cellulosimicrobium cellulans 191 (Equação 1).

Atividade de $\beta-1,3$ glucanase $=0,26+0,17 . \mathrm{pH}(\mathrm{L})+0,08$. agitação $(\mathrm{L})+0,03 \cdot \mathrm{pH}(\mathrm{L})$. temperatura $(\mathrm{L})+0,06 \cdot \mathrm{pH}(\mathrm{L})$. agitação $(\mathrm{L})+0,03$. temperatura $(\mathrm{L})$. agitação $(\mathrm{L})$
Tabela 6. Resultados do coeficiente de regressão, erro padrão e limites de confiança no estudo do efeito das variáveis independentes na produção de $\beta-1,3$ glucanase.

\begin{tabular}{lcccc}
\hline Parâmetros & $\begin{array}{c}\text { Coeficiente } \\
\text { de regressão }\end{array}$ & $\begin{array}{c}\text { Erro } \\
\text { padrão }\end{array}$ & $\begin{array}{r}\text { Limite de } \\
\text { confiança } \\
(-95 \%)\end{array}$ & $\begin{array}{c}\text { Limite de } \\
\text { confiança } \\
(+95 \%)\end{array}$ \\
\hline Média & 0,26 & 0,003 & 0,2452 & 0,2712 \\
$1-$ pH (L)* & 0,17 & 0,004 & 0,1548 & 0,1852 \\
2 - Temperatura (L) & 0,02 & 0,004 & $-0,0002$ & 0,0302 \\
3 - Agitação (L) & 0,08 & 0,004 & 0,0623 & 0,0927 \\
$1 \times 2^{*}$ & 0,03 & 0,004 & 0,0123 & 0,0427 \\
$1 \times 3^{*}$ & 0,06 & 0,004 & 0,0398 & 0,0702 \\
$2 \times 3^{*}$ & 0,03 & 0,004 & 0,0148 & 0,0452 \\
\hline
\end{tabular}

*Parâmetros estatisticamente significativos; e (L) parâmetro linear.

Tabela 7. Análise de variância no estudo do efeito das variáveis independentes na produção de $\beta-1,3$ glucanase.

\begin{tabular}{lcccc}
\hline $\begin{array}{l}\text { Fonte de } \\
\text { variação }\end{array}$ & $\begin{array}{c}\text { Soma } \\
\text { quadrática }\end{array}$ & $\begin{array}{c}\text { Graus de } \\
\text { liberdade }\end{array}$ & $\begin{array}{c}\text { Média } \\
\text { quadrática }\end{array}$ & Teste Fcal \\
\hline Regressão & 0,3167 & 5 & 0,0633 & 23,88 \\
Resíduos & 0,0133 & 5 & 0,0027 & - \\
\hline Coeficiente de determinação: $\mathrm{R}^{2}: 0,96 ;$ Ftab & $=5,05 ;$ e Fcal/Ftab $=4,73$.
\end{tabular}

As Figuras 1a, d indicam que o aumento do $\mathrm{pH}$ e a manutenção da temperatura (dentro das faixas estudadas) são favoráveis para obtenção de altas atividades da $\beta-1,3$ glucanase pela linhagem C. cellulans 191. As Figuras 1b, e ilustram que o aumento do pH e da agitação implicam num ganho da produção da enzima, sendo que o mesmo acontece quando se aumenta a agitação e se mantém a temperatura entre 27 e $33^{\circ} \mathrm{C}$ (Figuras 1c, f).

He et al. (2003) otimizaram as condições de cultivo para a produção de $\beta$-glucanase por Bacillus subtilis ZJF 1A5, em frascos agitados. A temperatura apresentou grande efeito na produção da enzima, sendo a temperatura ótima de $37^{\circ} \mathrm{C}$; a atividade diminuiu significativamente quando se utilizaram temperaturas superiores a esta. A quantidade de meio de cultivo no frasco afetou substancialmente a produção de $\beta$-glucanase. $\mathrm{O}$ aumento da velocidade de agitação resultou no aumento da 
Produção de enzimas líticas
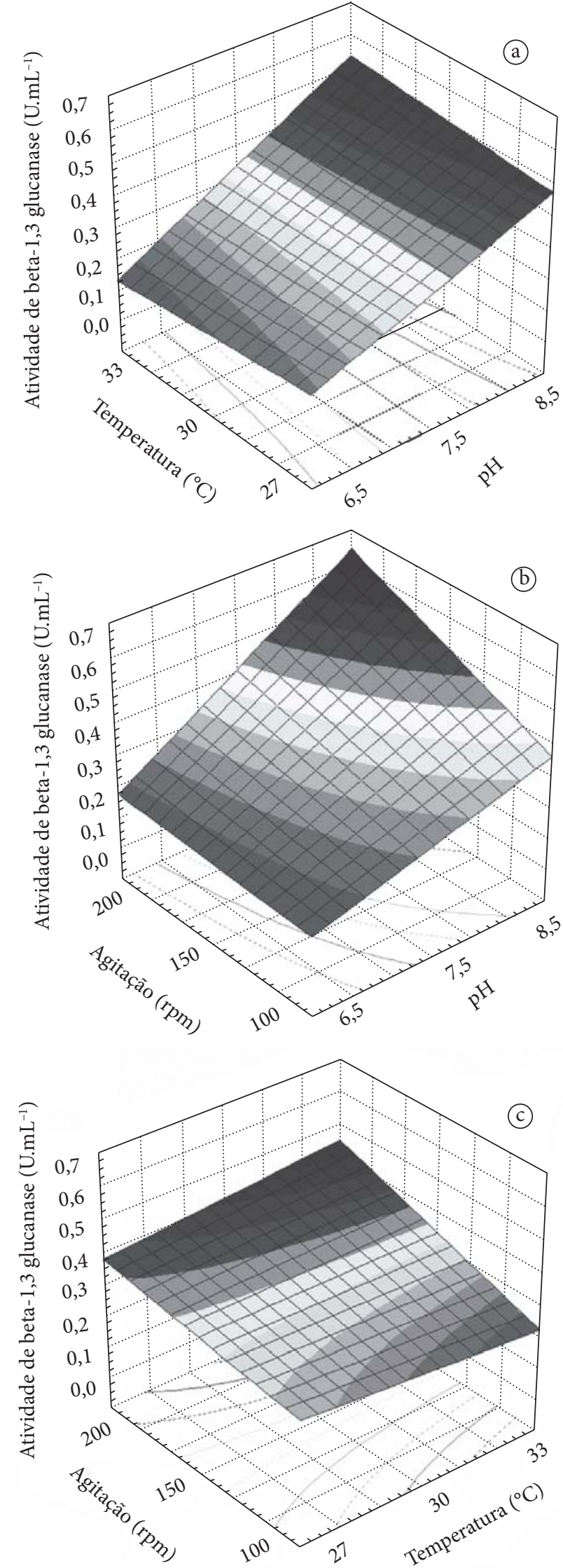
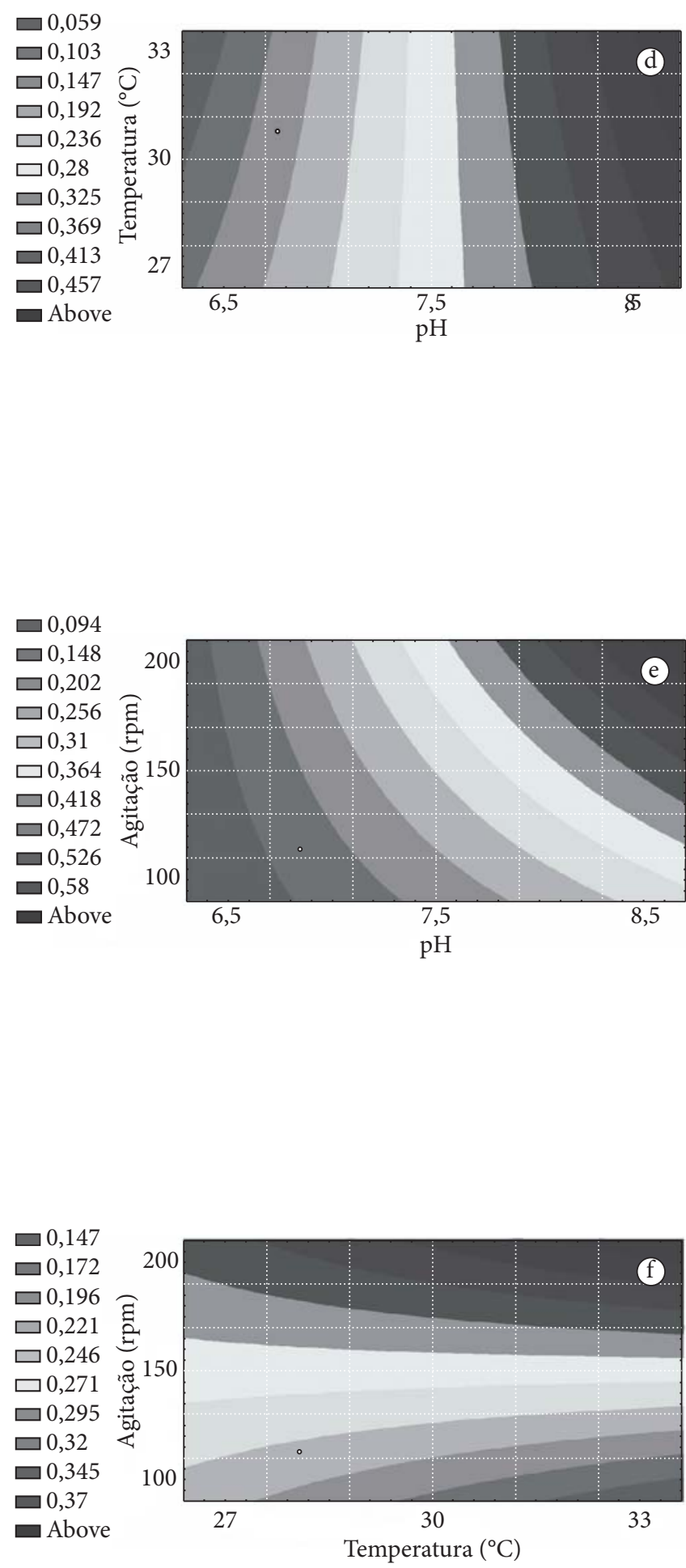

Figura 1. Superfícies de resposta e curvas de contorno obtidas no planejamento experimental fatorial para a produção de $\beta$-1,3 glucanase pela linhagem C. cellulans 191 como resposta para: a, d) pH e temperatura; b, e) pH e agitação; e c, f) temperatura e agitação. 
produção da enzima, mas foi dependente da concentração e da quantidade de meio de cultivo utilizado no frasco. Os resultados do planejamento fatorial fracionário mostraram que o tempo de crescimento e tamanho do inóculo e a velocidade de agitação dos frascos foram fatores fundamentais para a produção de $\beta$-glucanase e para o período de tempo para se obter a mais alta atividade.

No presente trabalho o planejamento fatorial indicou que o pH, a agitação e as interações entre todos os parâmetros influenciaram a produção da $\beta-1,3$ glucanase pela linhagem C. cellulans 191, enquanto a temperatura sozinha não apresentou nenhum efeito na resposta. A produção da enzima foi conduzida em frascos aletados, os quais permitem maior aeração do meio, nas condições selecionadas através do planejamento experimental (pH 7,5, $30^{\circ} \mathrm{C}$ e $200 \mathrm{rpm}$ ), sendo obtido 1,14 U.mL ${ }^{-1}$ de $\beta-1,3$ glucanase após 24 horas de fermentação.

Soares (2002) verificou que a linhagem Cellulosimicrobium cellulans 191 cultivada no meio A contendo $1 \%$ de parede celular extraída mecanicamente em Dyno-Mill produziu atividade de $\beta$-1,3 glucanase (0,59 U.mL $\left.\mathrm{mL}^{-1}\right)$ 4,2 vezes maior quando comparada com o estudo realizado por Ferro (2002), em que foi obtido 0,14 U.mL $\mathrm{mL}^{-1}$ de $\beta-1,3$ glucanase em meio de cultivo descrito por Scott e Schekman (1980).

Neste presente trabalho foi verificado que a mesma linhagem produziu inicialmente 0,64 U.mL $L^{-1}$ de $\beta-1,3$ glucanase (Tabela 4 e Ensaio 8) e em frascos aletados 1,14 U.mL ${ }^{-1}$. As condições selecionadas através do planejamento experimental e aplicadas no cultivo do microrganismo em frascos aletados implicaram na produção de $\beta$-1,3 glucanase aproximadamente 1,9 vezes maior que a obtida por Soares (2002).

\section{Estudo da produção de proteases}

Foi realizado um planejamento fatorial $2^{3}+3$ pontos centrais para avaliar as variáveis independentes $\mathrm{pH}$, temperatura e agitação dos frascos na produção de proteases pela linhagem Cellulosimicrobium cellulans 191.

A Tabela 8 mostra o planejamento fatorial para a produção de protease, com seus valores reais e codificados para cada ensaio, assim como a variável dependente: atividade de protease lítica (U.mL $\left.L^{-1}\right)$.

A análise estatística foi realizada com os valores de atividade enzimática obtidos após 30 horas de fermentação, em que foi obtida a maior atividade de protease (Ensaio 5) (Tabela 8).

Analisando os valores de atividade obtidos na Tabela 8 após 30 horas de fermentação, verifica-se um incremento na atividade de protease ao longo do planejamento, variando de atividade de 0,14 U.mL ${ }^{-1}$ para o ensaio 4 ( $\mathrm{pH} 9,5,40^{\circ} \mathrm{C}$ e 100 ) até $4,25 \mathrm{U} \cdot \mathrm{mL}^{-1}$

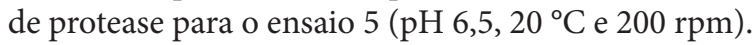

A Tabela 9 apresenta o efeito das variáveis sobre a produção de proteases. $\mathrm{O}$ pH foi o único parâmetro estudado que exerceu algum efeito estatisticamente significativo sob a produção enzimática. $\mathrm{O}$ efeito do $\mathrm{pH}$ foi negativo indicando que um incremento desta variável induziria uma diminuição da produção de protease. Os parâmetros temperatura, agitação dos frascos e as interações de todas as variáveis independentes não apresentaram efeito estatisticamente significativo na produção da protease. Dessa forma verificou-se que as condições para se obter maior produção de protease pela linhagem $C$. cellulans 191, dentre os valores estudados, são valores de $\mathrm{pH}$ abaixo de 9,5 . As condições de temperatura e a agitação, respectivamente, $30^{\circ} \mathrm{C}$ e $150 \mathrm{rpm}$, foram mantidas iguais às condições originais de fermentação.

A Tabela 10 apresenta os coeficientes de regressão, erros padrão e limites de confiança para a atividade de protease.

A validade do modelo foi verificada pela Análise de Variância (ANOVA) apresentada na Tabela 11. O coeficiente de determinação obtido foi de 0,94 . O valor do teste $F$ calculado foi comparado ao valor do teste $F$ tabelado para a distribuição de $\mathrm{F}$ a $95 \%$ de nível de confiança com os respectivos graus de liberdade. O F calculado para a produção de protease pela linhagem da C. cellulans 191 foi 26,38 vezes maior que o $\mathrm{F}$ tabelado, indicando que o modelo de primeira ordem é estatisticamente significativo e preditivo e descreve as respostas em função das variáveis analisadas.

Os coeficientes de regressão não estatisticamente significativos a 95\% de nível de confiança foram excluídos do modelo, sendo incorporados no resíduo total. A partir da validação dos parâmetros de estudo, obteve-se o modelo linear que representa o comportamento da atividade enzimática e que descreve as superfícies de resposta e curvas de contorno (Figura 2) da atividade de protease da linhagem C. cellulans 191 (Equação 2).

Atividade de protease $=2,27-1,84 . \mathrm{pH}(\mathrm{L})$

A Figura 2 indica que para a variável $\mathrm{pH}$, a faixa em que se obteria a maior atividade de protease seria abaixo de 9,5, sendo que a maior atividade foi observada em $\mathrm{pH}$ 6,5. Segundo Santos (2004), a faixa ótima de $\mathrm{pH}$ de muitas proteases que lisam leveduras está entre 8,0 e 10,0, indicando para o presente estudo que valores superiores a 8,0 para a protease lítica da linhagem C. cellulans 191 podem ter provocado queda na produção de protease, provavelmente pela inibição do crescimento microbiano.

As condições ótimas para a produção de protease ainda não foram encontradas. A Figura 2 também sugere que a diminuição do $\mathrm{pH}$ para abaixo de 6,5 poderia acarretar no aumento da atividade enzimática. $O$ ponto de inflexão da curva poderia ser obtido com a inclusão de pontos axiais num planejamento composto central rotacional.

\section{Estudo da produção de quitinases}

Foi realizado um planejamento fatorial $2^{3}+3$ pontos centrais para avaliar as variáveis independentes $\mathrm{pH}$, temperatura e agitação na produção de quitinase pela linhagem C. cellulans 191.

A Tabela 12 mostra o planejamento fatorial para a produção de quitinase, com seus valores reais e codificados para cada ensaio, assim como a variável dependente: atividade de quitinase $\left(\mathrm{U} \cdot \mathrm{mL}^{-1}\right)$. 
Tabela 8. Estudo do efeito de pH, temperatura e agitação na produção de protease pela linhagem C. cellulans 191.

\begin{tabular}{|c|c|c|c|c|c|c|}
\hline \multirow[t]{3}{*}{ Ensaios $^{*}$} & \multirow[t]{3}{*}{$\mathrm{pH}$} & \multirow[t]{3}{*}{ Temperatura $\left({ }^{\circ} \mathrm{C}\right)$} & \multirow[t]{3}{*}{ Agitação (rpm) } & \multicolumn{3}{|c|}{ Tempo de fermentação } \\
\hline & & & & 24 horas & 30 horas & 36 horas \\
\hline & & & & \multicolumn{3}{|c|}{ Atividade de protease $\left(\mathrm{U} \cdot \mathrm{mL}^{-1}\right)$} \\
\hline 1 & $-1(6,5)$ & $-1(20)$ & $-1(100)$ & 3,68 & 4,04 & 3,57 \\
\hline 2 & $+1(9,5)$ & $-1(20)$ & $-1(100)$ & 0,55 & 0,40 & 0,63 \\
\hline 3 & $-1(6,5)$ & $+1(40)$ & $-1(100)$ & 2,60 & 3,98 & 3,21 \\
\hline 4 & $+1(9,5)$ & $+1(40)$ & $-1(100)$ & 0,00 & 0,14 & 0,00 \\
\hline 5 & $-1(6,5)$ & $-1(20)$ & $+1(200)$ & 3,06 & 4,25 & 3,29 \\
\hline 6 & $+1(9,5)$ & $-1(20)$ & $+1(200)$ & 0,15 & 0,17 & 0,21 \\
\hline 7 & $-1(6,5)$ & $+1(40)$ & $+1(200)$ & 3,00 & 3,33 & 2,04 \\
\hline 8 & $+1(9,5)$ & $+1(40)$ & $+1(200)$ & 0,03 & 0,19 & 0,00 \\
\hline 9 & $0(8,0)$ & $0(30)$ & $0(150)$ & 2,75 & 2,96 & 2,3 \\
\hline 10 & $0(8,0)$ & $0(30)$ & $0(150)$ & 3,01 & 2,77 & 2,36 \\
\hline 11 & $0(8,0)$ & $0(30)$ & $0(150)$ & 2,64 & 2,74 & 2,65 \\
\hline
\end{tabular}

*Aleatorizados previamente à experimentação.

Tabela 9. Estimativa dos efeitos das variáveis independentes na produção de proteases.

\begin{tabular}{lrcrc}
\hline \multicolumn{1}{c}{ Parâmetros } & Efeito & Erro padrão & \multicolumn{1}{c}{$\mathrm{t}(2)$} & $\mathrm{p}$ \\
\hline Média & 2,27 & 0,036 & 63,11 & 0,0003 \\
1 - pH (L) & $-3,68$ & 0,084 & $-43,56$ & 0,0005 \\
2 - Temperatura (L) & $-0,31$ & 0,084 & $-3,62$ & 0,0687 \\
3 - Agitação (L) & $-0,16$ & 0,084 & $-1,84$ & 0,2076 \\
$1 \times 2$ & 0,19 & 0,084 & 2,19 & 0,1596 \\
$1 \times 3$ & 0,07 & 0,084 & 0,77 & 0,5216 \\
$2 \times 3$ & $-0,15$ & 0,084 & $-1,72$ & 0,2278 \\
\hline
\end{tabular}

${ }^{*}$ Parâmetros estatisticamente significativos; e (L) parâmetro linear.

Tabela 10. Resultados do coeficiente de regressão, erro padrão e limites de confiança no estudo do efeito das variáveis independentes na produção de proteases.

\begin{tabular}{lcccc}
\hline Parâmetros & $\begin{array}{c}\text { Coeficiente de } \\
\text { regressão }\end{array}$ & $\begin{array}{c}\text { Erro } \\
\text { padrão }\end{array}$ & $\begin{array}{c}\text { Limite de } \\
\text { confiança } \\
(-95 \%)\end{array}$ & $\begin{array}{c}\text { Limite de } \\
\text { confiança } \\
(+95 \%)\end{array}$ \\
\hline Média & 2,27 & 0,036 & 2,12 & 2,42 \\
1 - pH (L)* & $-1,84$ & 0,042 & $-2,02$ & $-1,66$ \\
2 - Temperatura (L) & $-0,15$ & 0,042 & $-0,33$ & 0,03 \\
3 - Agitação (L) & $-0,08$ & 0,042 & $-0,26$ & 0,10 \\
$1 \times 2$ & 0,09 & 0,042 & $-0,09$ & 0,27 \\
$1 \times 3$ & 0,03 & 0,042 & $-0,15$ & 0,21 \\
$2 \times 3$ & $-0,07$ & 0,042 & $-0,25$ & 0,11 \\
\hline
\end{tabular}

*Parâmetros estatisticamente significativos; e (L) parâmetro linear.

Tabela 11. Análise de variância no estudo do efeito das variáveis independentes na produção de proteases.

\begin{tabular}{lcccc}
\hline $\begin{array}{l}\text { Fonte de } \\
\text { variação }\end{array}$ & $\begin{array}{c}\text { Soma } \\
\text { quadrática }\end{array}$ & $\begin{array}{c}\text { Graus de } \\
\text { liberdade }\end{array}$ & $\begin{array}{c}\text { Média } \\
\text { quadrática }\end{array}$ & Teste Fcal \\
\hline Regressão & 27,011 & 1 & 27,011 & 134,54 \\
Resíduos & 1,807 & 9 & 0,201 & \\
\hline
\end{tabular}

Coeficiente de determinação: $\mathrm{R}^{2}: 0,94 ; \mathrm{Ftab}_{0,95 ; 1 ; 9}=5,12$; e Fcal/Ftab = 26,38.

A análise estatística foi realizada com os valores de atividade enzimática obtidos após 72 horas de fermentação, onde se encontra o maior valor de quitinase (Ensaio 5) (Tabela 12).
Analisando os valores de atividade obtidos na Tabela 12 após 72 horas de fermentação, verifica-se um aumento na atividade de quitinase ao longo do planejamento, variando

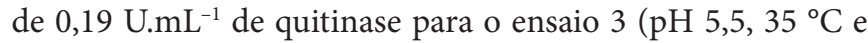
$100 \mathrm{rpm}$ ) até 7,06 U.mL ${ }^{-1}$ de quitinase para o ensaio 5 (pH 5,5, $25^{\circ} \mathrm{C}$ e $200 \mathrm{rpm}$ ). A atividade de quitinase obtida pela fermentação da linhagem C. cellulans $191 \mathrm{em}$ meio de cultivo C contendo $1,5 \%$ de quitina neutralizada com pH inicial de 5,5, a $25^{\circ} \mathrm{C}$ e $200 \mathrm{rpm}$ de agitação após 72 horas de fermentação foi de 7,06 U.mL $\mathrm{mL}^{-1}$, indicando que foi obtida maior produção da enzima quando comparada com o estudo realizado por Yamaguchi (2003), em que foi obtido 4,03 U.mL ${ }^{-1}$ utilizando a linhagem C. cellulans FXX e a mesma metodologia de determinação da atividade enzimática.

A Tabela 13 apresenta o efeito das variáveis sobre a produção de quitinase. $\mathrm{O}$ pH e a temperatura apresentaram efeitos negativos significativos na atividade enzimática; enquanto que a variável agitação dos frascos exerceu efeito positivo significativo. Todas as interações entre as variáveis independentes apresentaram efeito negativo na resposta. A variável agitação dos frascos exerceu maior influência na produção enzimática, seguida da temperatura. $\mathrm{O} \mathrm{pH}$ individualmente apresentou menor efeito na atividade enzimática. Dessa forma, verificouse que as condições para se obter maior produção de quitinase, dentre os valores estudados, são: valores de $\mathrm{pH}$ abaixo de 7,5, temperaturas abaixo de $35{ }^{\circ} \mathrm{C}$ e agitação dos frascos superior a $100 \mathrm{rpm}$. Para a continuidade do trabalho de produção de quitinase foram escolhidas as seguintes condições de produção de quitinase pela linhagem C. cellulans 191: pH 5,5, $25^{\circ} \mathrm{C}$ e $200 \mathrm{rpm}$ para agitação dos frascos.

A Tabela 14 apresenta os coeficientes de regressão, erros padrão e limites de confiança para a produção de quitinases.

A validade do modelo foi verificada pela Análise de Variância (ANOVA) apresentada na Tabela 15. A medida de correlação utilizada para se estimar o modelo foi o coeficiente de determinação $\left(\mathrm{R}^{2}\right)$. Quanto maior a proximidade de $\mathrm{R}^{2} \mathrm{da}$ unidade 1 melhor a correlação entre os valores de atividade preditos pelo modelo e os valores observados. Foi obtido 

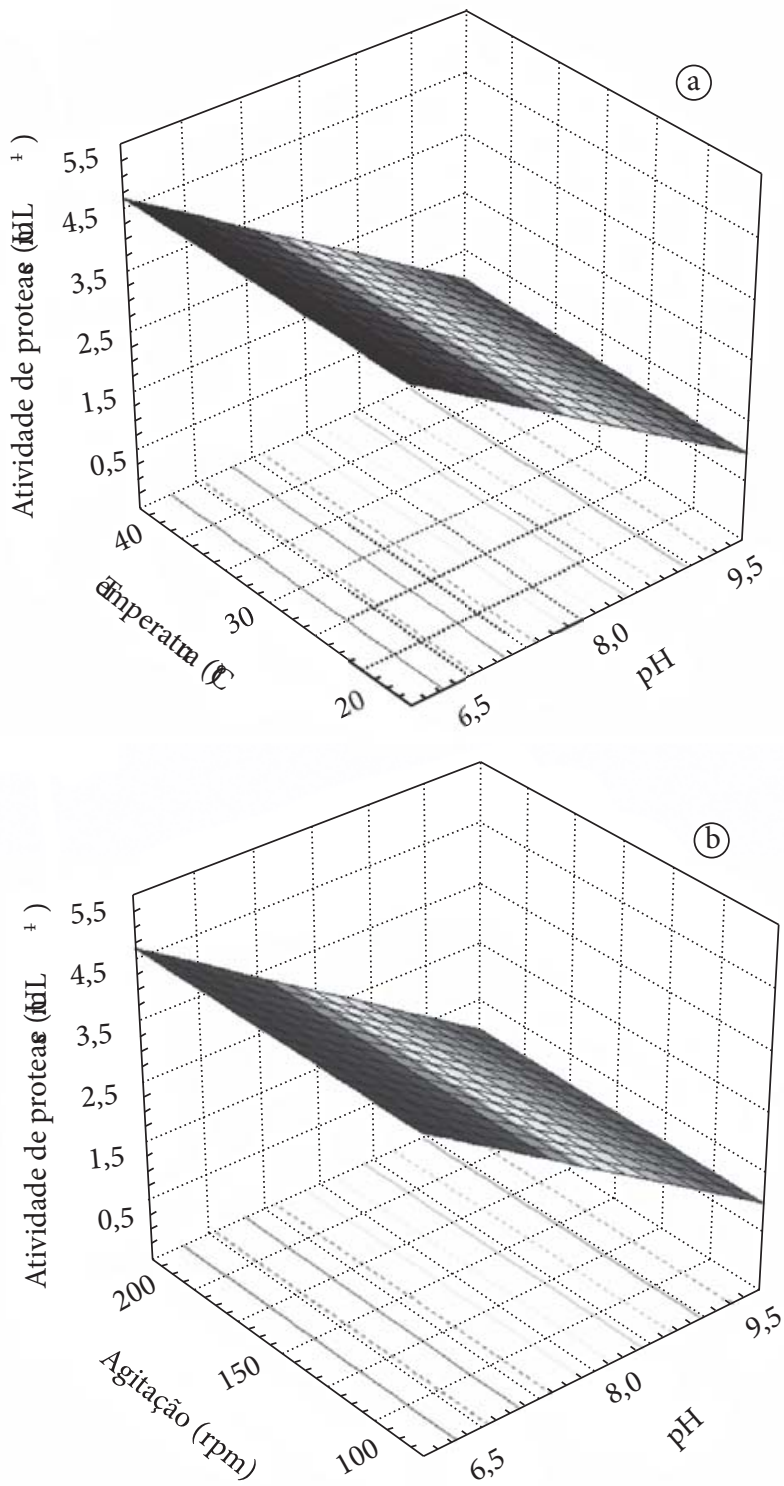
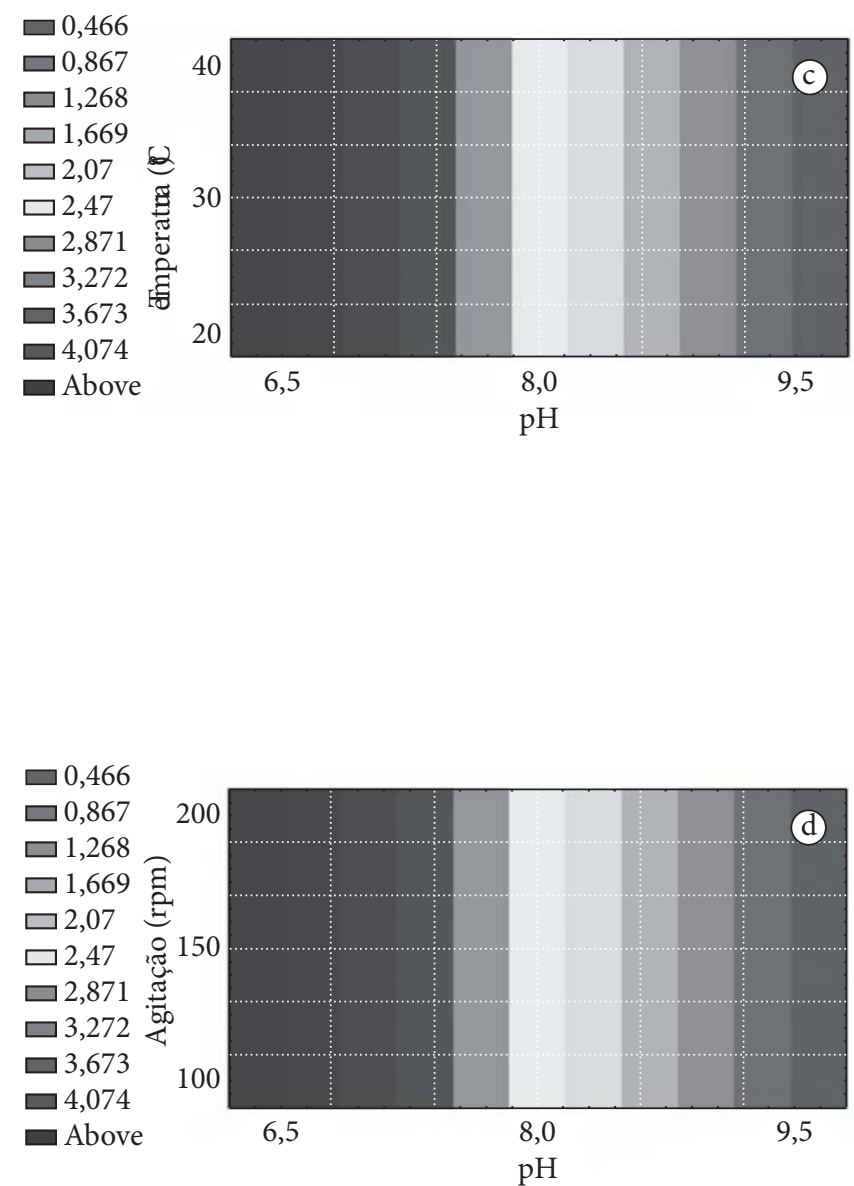

Figura 2. Superfícies de resposta e curvas de contorno obtidas no planejamento experimental fatorial para a produção de protease pela linhagem de C. cellulans 191 como resposta para a, c) pH e temperatura; e b, d) pH e agitação.

Tabela 12. Estudo do efeito de $\mathrm{pH}$, temperatura e agitação na produção de quitinase pela linhagem C. cellulans 191.

\begin{tabular}{|c|c|c|c|c|c|c|}
\hline \multirow[t]{3}{*}{ Ensaios* } & \multirow[t]{3}{*}{$\mathrm{pH}$} & \multirow[t]{3}{*}{ Temperatura $\left({ }^{\circ} \mathrm{C}\right)$} & \multirow[t]{3}{*}{ Agitação (rpm) } & \multicolumn{3}{|c|}{ Tempo de fermentação } \\
\hline & & & & 72 horas & 96 horas & 120 horas \\
\hline & & & & \multicolumn{3}{|c|}{ Atividade de quitinase $\left(\mathrm{U} \cdot \mathrm{mL}^{-1}\right)$} \\
\hline 1 & $-1(5,5)$ & $-1(25)$ & $-1(100)$ & 0,37 & 0,84 & 0,96 \\
\hline 2 & $+1(7,5)$ & $-1(25)$ & $-1(100)$ & 0,70 & 0,98 & 0,97 \\
\hline 3 & $-1(5,5)$ & $+1(35)$ & $-1(100)$ & 0,19 & 0,51 & 0,59 \\
\hline 4 & $+1(7,5)$ & $+1(35)$ & $-1(100)$ & 0,44 & 0,82 & 0,60 \\
\hline 5 & $-1(5,5)$ & $-1(25)$ & $+1(200)$ & 7,06 & 6,52 & 2,70 \\
\hline 6 & $+1(7,5)$ & $-1(25)$ & $+1(200)$ & 5,88 & 5,61 & 5,40 \\
\hline 7 & $-1(5,5)$ & $+1(35)$ & $+1(200)$ & 4,45 & 3,97 & 0,72 \\
\hline 8 & $+1(7,5)$ & $+1(35)$ & $+1(200)$ & 1,55 & 0,53 & 0,07 \\
\hline 9 & $0(6,5)$ & $0(30)$ & $0(150)$ & 2,47 & 2,92 & 0,87 \\
\hline 10 & $0(6,5)$ & $0(30)$ & $0(150)$ & 2,46 & 2,94 & 0,85 \\
\hline 11 & $0(6,5)$ & $0(30)$ & $0(150)$ & 2,49 & 2,93 & 0,83 \\
\hline
\end{tabular}

*Aleatorizados previamente à experimentação. 
Tabela 13. Estimativa dos efeitos das variáveis independentes na produção de quitinase.

\begin{tabular}{lrcrc}
\hline \multicolumn{1}{c}{ Parâmetros } & Efeito & Erro padrão & \multicolumn{1}{c}{$\mathrm{t}(2)$} & $\mathrm{p}$ \\
\hline Média & 2,55 & 0,005 & 553,86 & 0,000003 \\
$1-\mathrm{pH}(\mathrm{L})^{*}$ & $-0,88$ & 0,011 & $-81,01$ & 0,000152 \\
2 - Temperatura $(\mathrm{L})^{*}$ & $-1,85$ & 0,011 & $-170,81$ & 0,000034 \\
3 - Agitação $(\mathrm{L})^{*}$ & 4,31 & 0,011 & 399,03 & 0,000006 \\
$1 \times 2^{*}$ & $-0,45$ & 0,011 & $-41,66$ & 0,000576 \\
$1 \times 3^{*}$ & $-1,17$ & 0,011 & $-107,86$ & 0,000086 \\
$2 \times 3^{*}$ & $-1,63$ & 0,011 & $-150,45$ & 0,000044 \\
\hline${ }^{*}$ Parâmetros estatisticamente significativos; $\mathrm{e}(\mathrm{L})$ parâmetro linear.
\end{tabular}

Tabela 14. Resultados do coeficiente de regressão, erro padrão e limites de confiança no estudo do efeito das variáveis independentes na produção de quitinase.

\begin{tabular}{lrrrr}
\hline \multicolumn{1}{c}{ Parâmetros } & $\begin{array}{c}\text { Coeficiente } \\
\text { de regressão }\end{array}$ & $\begin{array}{c}\text { Erro } \\
\text { padrão }\end{array}$ & $\begin{array}{c}\text { Limite de } \\
\text { confiança } \\
(-95 \%)\end{array}$ & $\begin{array}{c}\text { Limite de } \\
\text { confiança } \\
(+95 \%)\end{array}$ \\
\hline Média & 2,55 & 0,005 & 2,53 & 2,57 \\
1 - pH $(\mathrm{L})^{*}$ & $-0,44$ & 0,005 & $-0,46$ & $-0,41$ \\
2 - Temperatura (L) & $-0,92$ & 0,005 & $-0,95$ & $-0,90$ \\
$3-$ Agitação (L) & 2,16 & 0,005 & 2,13 & 2,18 \\
$1 \times 2^{*}$ & $-0,23$ & 0,005 & $-0,25$ & $-0,20$ \\
$1 \times 3^{*}$ & $-0,58$ & 0,005 & $-0,61$ & $-0,56$ \\
$2 \times 3^{*}$ & $-0,81$ & 0,005 & $-0,84$ & $-0,79$ \\
\hline
\end{tabular}

${ }^{*}$ Parâmetros estatisticamente significativos; e (L) parâmetro linear.

Tabela 15. Análise de variância no estudo do efeito das variáveis independentes ( $\mathrm{pH}$, temperatura e agitação) na produção de quitinases.

\begin{tabular}{lcccc}
\hline $\begin{array}{l}\text { Fonte de } \\
\text { variação }\end{array}$ & $\begin{array}{c}\text { Soma } \\
\text { quadrática }\end{array}$ & $\begin{array}{c}\text { Graus de } \\
\text { liberdade }\end{array}$ & $\begin{array}{c}\text { Média } \\
\text { quadrática }\end{array}$ & Teste Fcal \\
\hline Regressão & 53,89 & 6 & 8,98 & 99,39 \\
Resíduos & 0,36 & 4 & 0,09 & \\
\hline Coeficiente de determinac̃o: $\mathrm{R}^{2}$ : 0,99; & & 6 &
\end{tabular}

Coeficiente de determinação: $\mathrm{R}^{2}: 0,99 ; \mathrm{Ftab}_{0,95 ; 6 ; 4}=6,16 ;$ e Fcal/Ftab $=16,13$.

um valor de $\mathrm{R}^{2}$ de 0,99 indicando uma excelente correlação. $\mathrm{O}$ valor do coeficiente de determinação de 0,99 indica que apenas $1 \%$ do total da variação das respostas obtidas não é explicado pelo modelo. $\mathrm{O}$ valor do teste $F$ calculado foi comparado ao valor do teste $F$ tabelado para a distribuição de $\mathrm{F}$ a $95 \%$ de nível de confiança com os respectivos graus de liberdade. O F calculado para a produção de quitinase pela linhagem C. cellulans 191 foi de 16,13 vezes maior que o $\mathrm{F}$ tabelado, indicando que o modelo de primeira ordem é estatisticamente significativo e preditivo e descreve as respostas em função das variáveis analisadas.

A partir da validação dos parâmetros de estudo, obteve-se o modelo linear que representa o comportamento da atividade enzimática e que descreve as superfícies de resposta e curvas de contorno (Figura 3) da atividade de quitinase da linhagem C. cellulans 191 (Equação 3).

Atividade de quitinase $=2,55-0,44 . \mathrm{pH}(\mathrm{L})$ - 0,92 . temperatura (L) + 2,16. agitação (L) - 0,23 pH (L) . temperatura (L) - 0,58 pH (L) . agitação (L) - 0,81 temperatura (L) . agitação (L)
A Figura 3 mostra os efeitos das variáveis $\mathrm{pH}$, temperatura e agitação na produção de quitinase. Pode-se observar que, dentro da faixa estudada de $\mathrm{pH}$, há uma tendência em se obter uma maior produção da enzima com valores entre 5,5 e 6,5 (Figuras 3a, 3d, 3b e 3e). As Figuras 3a, 3d, 3c e 3f indicam que há um incremento na obtenção de quitinase quando se utilizou temperaturas menores que $30^{\circ} \mathrm{C}$, sendo obtidas maiores atividades a $25^{\circ} \mathrm{C}$. Pode-se verificar que a produção dessa enzima requer altas agitações, superiores a $150 \mathrm{rpm}$, sendo que a maior produção obtida foi a $200 \mathrm{rpm}$, como mostram as Figuras $3 \mathrm{~b}$ e $3 \mathrm{e}$.

\section{Conclusões}

As enzimas líticas são utilizadas para a lise de leveduras e fungos, sendo que a obtenção de altas atividades enzimáticas é de fundamental importância para a industrialização das preparações, seja na forma bruta ou purificada.

Os planejamentos experimentais e a metodologia de superfície de resposta permitiram verificar a influência do $\mathrm{pH}$, temperatura e agitação na produção de $\beta-1,3$ glucanases, proteases e quitinases da linhagem Cellulosimicrobium cellulans 191. Foram verificadas atividades enzimáticas superiores às encontradas com as condições originais de fermentação. O estudo também forneceu informações importantes para a otimização da produção das enzimas.

\section{Agradecimentos}

À FAPESP pelo apoio financeiro referente às bolsas de Mestrado e Doutorado.

\section{Referências bibliográficas}

ADINARAYANA, K.; ELLAINE, P. Response surface optimization of the critical medium components for the production of alkaline protease by a newly isolated Bacillus sp. Journal of Pharmacy and Pharmaceutical Sciences, v. 5, n. 3, p. 272, 2002.

ANDREWS, B. A.; ASENJO, J. A. Continuous-culture studies of synthesis and regulation of extracellular $\beta(1-3)$ glucanase and protease enzymes from Oerskovia xanthineolytica. Biotechnology and Bioengineering, v. 30, n. 5, p. 628, 1987a.

ANDREWS, B. A.; ASENJO, J. A. Enzymatic lysis and disruption of microbial cells. Trends and Biotechnology, v. 5, n. 10, p. 273, $1987 b$.

BESHAY, U. et al. $\beta$-Glucanase production from genetically modified recombinant Escherichia coli: Effect of growth substrates and development of a culture medium in shake flasks and stirred tank bioreactor. Process Biochemistry, v. 39, n. 3, p. 307, 2003.

FERRO, L. A. Produção, Purificação e Caracterização da enzima $\beta-1,3$ glucanase de Cellulomonas cellulans YLM-B191-1 e ação da enzima na parede celular de leveduras. Campinas, 2002, 175p. Tese (Doutorado em Ciência de Alimentos) - Faculdade de Engenharia de Alimentos, Universidade Estadual de Campinas (Unicamp).

FLEURI, L. F; SATO, H. H. Produção, purificação, clonagem e aplicação de enzimas líticas. Química Nova, São Paulo, v. 28, n. 5, p. 871, 2005.

HE, G. Q. et al. Optimization of cultural conditions for thermostable beta-1,3-1,4-glucanase production by Bacillus subtilis ZJF-1A5. 

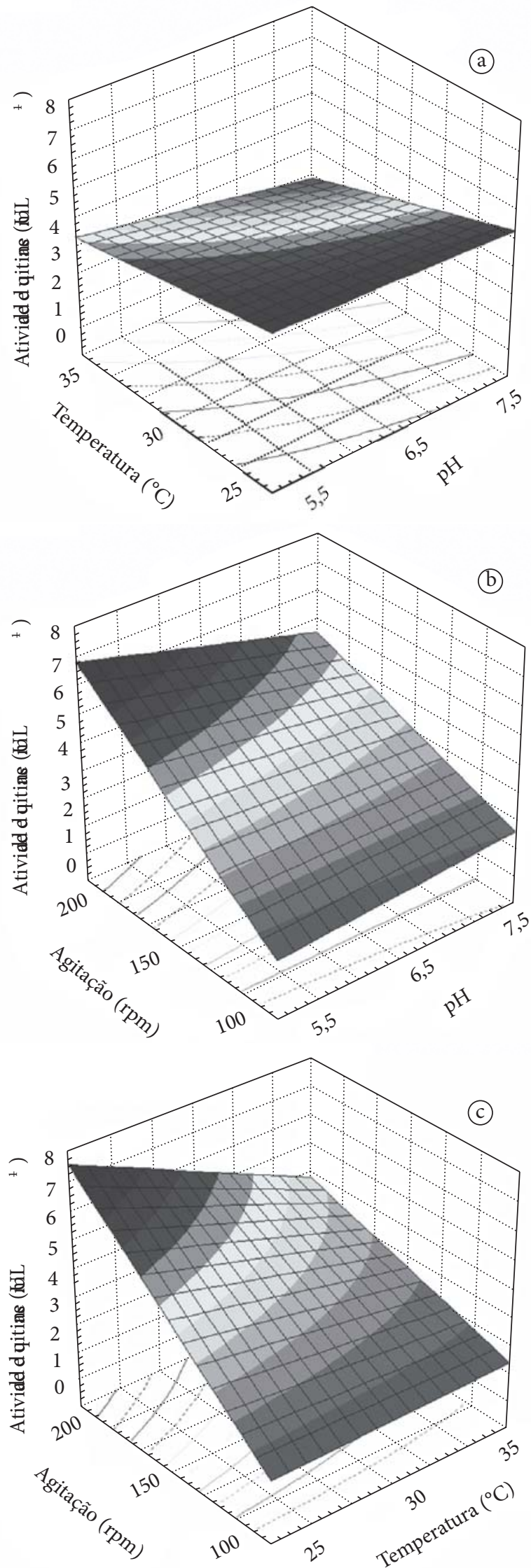
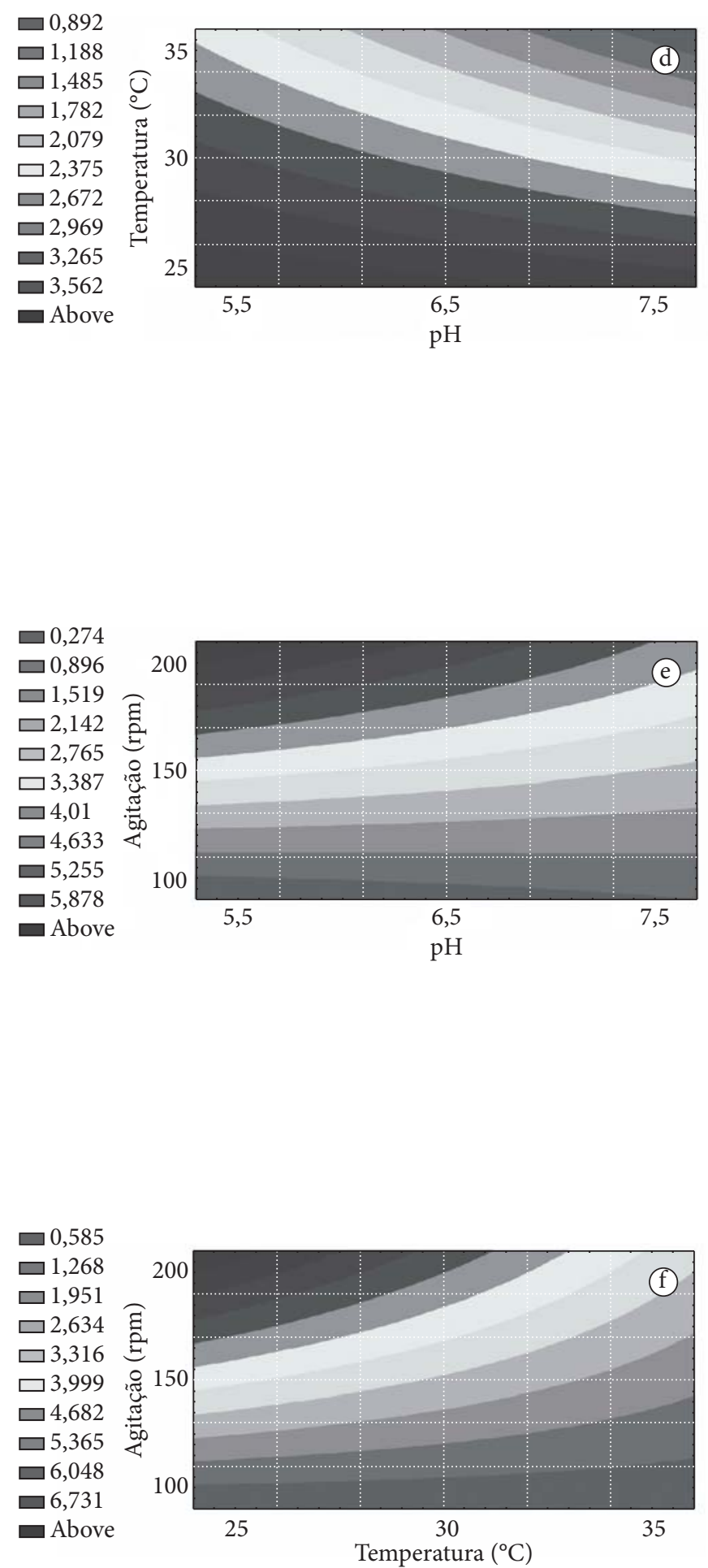

Figura 3. Superfícies de resposta e curvas de contorno obtidas no planejamento experimental fatorial para a produção de quitinase pela linhagem C. cellulans 191 como resposta para: a, d) pH e temperatura; b, e) pH e agitação; e c, f) temperatura e agitação. 
Journal of Zhejiang University Science, Hangzhou, v. 4, n. 6, p. 719, 2003.

NETO, B. D. B.; SCARMINIO, I. S.; BRUNS, R. E. Em Como fazer experimentos: planejamento e otimização de experimentos. Campinas: ed. Unicamp, 2001, p. 480.

OBATA, T.; IWATA, H.; NAMBA, Y. The synergistic effects among $\beta-1,3$ glucanase from Oerskovia sp CK. on lysis of viable yeast cell. Agricultural and Biological Chemistry, Tokyo, v. 41, p. 2387, 1977.

PATIL, R. S.; GHORMADE, V.; DESHPANDE, M. V. Review: Chitinolytic enzymes: an exploration. Enzyme and Microbial Technology, v. 26, n. 7, p. 473, 2000.

RÉISSIG, J. L.; STROMINGER, J. L.; LELOIR, L. F. A modified colorimetric method for the estimation of $\mathrm{N}$-acetylamino sugar. Journal of Biological Chemistry, New York, v. 217, n. 1, p. 959, 1955.

ROWLEY, B. I.; BULL, A. T. Isolation of a yeast-lysing Arthrobacter species and the production of the lytic enzyme complex in batch and continuous-flow fermentors. Biotechnology and Bioengineering, v. 19 , n. 6 , p. $879,1977$.

SAEKI, K. et al. Purification and characterization of a yeast lytic $\beta$-1,3-glucanase from Oerskovia xanthineolytica TK-1. Journal of Fermentation and Bioengineering, v. 78, n. 6, p. 407, 1994.

SAHAI, A. S.; MANOCHA, M. S. Chitinase of fungi and plants: their involvement in morphogenesis and host-parasite interactions. FEMS Microbiology Reviews, v. 11, p. 317, 1993.

SANDHU, D. K.; WADHWA, V.; BAGGA, P. S. Use of lytic enzymes for protoplast production in Trichoderma reesei QM9414. Enzyme and Microbial Technology, v. 11, p. 21, 1989.

SANTOS, L. F. Produção, purificação, caracterização e estudo da aplicação de uma protease alcalina produzida por Cellulosimicrobium cellulans 191. Campinas, 2004, 97 p. Tese (Doutorado em Ciência de Alimentos) - Faculdade de Engenharia de Alimentos, Universidade Estadual de Campinas (Unicamp).

SANTOS, L. F. Caracterização bioquímica da protease lítica produzida por Cellulomonas cartae 191 e estudo da lise enzimática de leveduras. Campinas, 2000, 71 p. Dissertação
(Mestrado em Ciência de Alimentos) - Faculdade de Engenharia de Alimentos, Universidade Estadual de Campinas (Unicamp).

SCOTT, J. H.; SCHEKMAN, R. Lyticase: endoglucanase and protease activities that act together in yeast cell lysis. Journal of Bacteriology, v. 142, n. 2, p. 414, 1980.

SElitrennikoff, C. P. Antifungal Proteins. Applied and Environmental Microbiology, v. 67, n. 7, p. 2883, 2001.

SOARES, G. A. M. Enzimas que lisam a parede celular de leveduras Clonagem e sequenciamento do gene da $\beta-1,3$ glucanase lítica de Cellulomonas cartae 191. Campinas, 2002, 113 p. Tese (Doutorado em Ciência de Alimentos) - Faculdade de Engenharia de Alimentos, Universidade Estadual de Campinas (Unicamp).

SOMOGYI, N. A new reagent for the determination of sugars. Journal of Biological Chemistry, New York, v. 195, p. 19, 1952.

STATSOFT. STATISTICA ${ }^{\circ} \mathbf{5 . 0}$ from Statsoft Inc. Tulsa, USA: Statsoft.

TANG, X. J. et al. Medium optimization for the production of thermal stable beta-glucanase by Bacillus subtilis ZJF-1A5 using response surface methodology. Bioresource Technology, v. 93, n. 2, p. 175, 2004.

THÉODORE, K.; PANDA, T. Application of response surface methodology to evaluate the influence of temperature and initial $\mathrm{pH}$ on the production of $\beta$-1,3-glucanase and carboxymethylcellulase from Trichoderma harzianum. Enzyme Microbial Technology, v. 17, n. 12, p. 1043, 1995.

VAIDYA, R.; VYAS, P.; CHHATPAR, H. S. Statistical optimization of medium components for the production of chitinase by Alcaligenes xylosoxydans. Enzyme Microbial Technology, v. 33, n. 1, p. 92, 2003.

YAMAGUCHI, M. M. Seleção, produção e caracterização da enzima quitinase. Campinas, 2003, 83 p. Tese (Doutorado em Ciência de Alimentos) - Faculdade de Engenharia de Alimentos, Universidade Estadual de Campinas (Unicamp).

YAMAMOTO, N. et al. Taxonomic studies on yeast-lysing bacteria, and a new species Rarobacter incanus Journal of General and Applied Microbiology, v. 39, p. 261, 1993. 